\title{
Self-Esteem, Self-Stigma, and Stigmatization among People with Mental Illness in Japan Who Have Work Experience
}

\author{
Hatsumi Yoshii ${ }^{*}$, Kouhei Akazawa ${ }^{2 \#, ~ H i d e m i t s u ~ S a i t o " ~}{ }^{1 \#}$ \\ ${ }^{1}$ Health Sciences, Tohoku University Graduate School of Medicine, Sendai, Japan \\ ${ }^{2}$ Department of Medical Informatics and Statistics, Niigata University Graduate School of Medicine, Niigata, \\ Japan \\ Email: "hatsumi@med.tohoku.ac.jp
}

Received 23 June 2016; accepted 19 July 2016; published 22 July 2016

Copyright (C) 2016 by authors and Scientific Research Publishing Inc.

This work is licensed under the Creative Commons Attribution International License (CC BY).

http://creativecommons.org/licenses/by/4.0/

(c) $\underset{\mathrm{EY}}{\mathrm{B}}$ Open Access

\begin{abstract}
Self-stigma of mental illness hinders work and reduces self-esteem. The aim of the study was to examine self-esteem, self-stigma, and stigmatisation among people with mental illness in Japan who had work experience. Survey respondents were 191 patients with mental illnesses in Japan. Self-esteem and self-stigma were measured, and associations between participants' characteristics and these variables were explored. Most study participants were males (69.1\%); 103 participants had schizophrenia (53.9\%). Self-esteem differed significantly by type of support facility, age at onset, psychiatric hospitalisation, income, part-time work, treatment at work, consultation, reasons for unemployment and motivations for employment. Significant negative influences on self-stigma were not living alone, not disclosing the illness to colleagues, not citing mental illness as a reason for unemployment and not working for a living. It is necessary to improve working environments to ensure that people with mental illnesses can work by introducing anti-stigma countermeasures.
\end{abstract}

\section{Keywords}

\section{Self-Esteem, Self-Stigma, Mental Illness, Work}

\footnotetext{
${ }^{*}$ Corresponding author.

"These authors contributed equally to this work.
}

How to cite this paper: Yoshii, H., Akazawa, K., \& Saito, H. (2016). Self-Esteem, Self-Stigma, and Stigmatization among People with Mental Illness in Japan Who Have Work Experience. Psychology, 7, 1174-1184. 


\section{Introduction}

Social reactions to mental illness add a dimension of suffering that has been described as a "second illness". The internalised stigma of mental illness impedes recovery and is associated with increased depression, perceptions of devaluation and discrimination, as well as reduced self-esteem, recovery orientation and empowerment (Boyd et al., 2014). In a study on self-stigma among people with mental illnesses, Corrigan et al. (2013) found a large and significant correlation between self-stigma and quality of life. A study of outpatients with schizophrenia spectrum disorders found a stronger association between insight and demoralisation at higher levels of selfstigma (Cavelti et al., 2012), and a study targeting people receiving compulsory community-based treatment services reported significant associations between level of self-stigma and psychiatric symptom severity, history of incarceration and history of homelessness (Livingston et al., 2011). Undermined by prejudice and discrimination, it is also common for people living with mental illness to internalise social stigma and become increasingly withdrawn and self-isolated, losing self-esteem and self-efficacy in the process (Corrigan et al., 2002; Watson et al., 2007). Self-esteem, in turn, has been shown to be related to household income, diagnosis, psychiatric symptoms, service satisfaction, perceived stigma and perceptions of social roles (Kahng \& Mowbray, 2005). In this way, self-stigma and reduced self-esteem negatively affect the lives of people with mental illnesses. Many people with mental illnesses experience stigma in the workplace, leading to self-stigma and worsening of selfesteem (Watson et al., 2007). However, an assessment among participants in an employment support programme found that, compared with unemployed participants, those who worked without experiencing discrimination had lower levels of self-stigma and stigma stress (Rüsch et al., 2014). These findings indicate the importance of considering self-stigma and self-esteem in supporting the employment of people with mental illnesses. We examined self-stigma, self-esteem, and stigmatisation among people with mental illnesses in Japan who had work experience. Based on previous research results, we hypothesized that psychiatric diagnosis, experience of psychiatric hospitalisation and income would be associated with self-esteem and self-stigma. Our study will contribute to improvement of QOL among people with mental illness.

\section{Methods}

\subsection{Setting and Participants}

We initially sent a letter of invitation by postal mail to the directors of the centres for transition support for employment, centres for support for employment and life of handicapped people, psychiatric day care centres and occupational centres for handicapped people in Japan. We then requested their participation in our research by telephone. After the directors agreed to participate by returning the letter of agreement, we sent them the questionnaire sheets, which were then distributed to participants. Each participant completed the questionnaire and returned it anonymously to the researchers by postal mail. We judged each participant to have given consent to participate when he or she, having received full information about the study, returned the completed questionnaire. Participants answered three sections; sociodemographics, self-esteem and self-stigma. This study was approved by the Medical Ethics Committee of Tohoku University.

\subsection{Questionnaire}

\subsubsection{Basic Demographic Characteristics and Stigmatization}

The participants provided demographic information on gender, age, type of support facility, educational attainment, family structure, contribution of living expenses, mental illness, age of onset, the medications they were currently using and the associated side-effects, mental hospital inpatient experience and number of hospital admissions, the number of jobs and job descriptions, type of employment, wages, unfair experiences at work, experiences of being treated coldly at work, reasons for being treated unfairly, whether they had been advised by their boss to quit work following suspension, disclosure of mental illness and reason for regretting disclosure, reasons for being denied employment, job rotation, reasons for retirement, reasons for working, whether they had been told to work by their family, and consulting for people with mental illness.

\subsubsection{Rosenberg Self-Esteem Scale Japanese Version (RSES-J)}

The Rosenberg Self-Esteem Scale (RSES) defines self-esteem as a global concept of the self and as reflecting a 
sense of worth or value, not as the possession or accumulation of specific qualities or abilities. Reported Cronbach's $\alpha$ coefficients for the scale have ranged from .83 to .99. The 1-week test-retest reliability was reported as .82 (Mimura \& Griffiths, 2007). We evaluated self-esteem using this scale, which consists of 10 four-point Likert-type questions, rated from strongly disagree $(=1)$ to strongly agree $(=4)$, with higher values indicating stronger self-esteem. The total possible score ranges from 10 to 40; higher scores indicate greater self-esteem. We used the Japanese version of the Rosenberg Self-Esteem Scale (RSES-J). The equivalence of the original RSES and RSES-J is indicated by a near-identical factor structure and structure coefficients, and similar internal consistency reliability (Mimura \& Griffiths, 2007).

\subsubsection{Workplace Social Distance Scale (WSDS)}

The WSDS was used to measure self-stigma among people with mental illness who had work experience (Yoshii et al., 2014). This scale measures the extent to which a respondent believes that they themselves would devalue or discriminate against someone with a mental illness. This scale was developed by rephrasing the eight items of the Japanese version of the Social Distance Scale (SDSJ) to make them applicable to work settings in Japan. The reliability and validity of the scale were examined among psychiatric patients in Japan. Cronbach's alpha coefficient for the scale was .753. The split-half reliability for the scale was .801, indicating good internal consistency reliability. The measure consists of eight four-level Likert-type items rated from strongly disagree $(=0)$ to strongly agree $(=3)$, with higher values indicating stronger stigma. Higher scores correspond to greater social distance. The scale elicits responses to mental illnesses and encourages the free expression of negative attitudes.

\subsection{Statistical Analysis}

All statistical analyses were performed using IBM SPSS Statistics for Windows, version 20.0 (Armonk, NY: IBM Corp). The Kruskal-Wallis test and the Mann-Whitney $U$ test were used to examine the associations between questionnaire scoresand participants' demographic characteristics (gender, age, type of support facility, educational attainment, family structure, contribution of living expenses, mental illness, age of onset, the medication (s) they were currently using and the associated side effects, mental hospital inpatient experience and number of hospital admissions, the number of jobs and job descriptions, type of employment, wage, unfair experiences at work, experiences of being treated coldly at work, reasons for being treated unfairly, whether they had been advised by their boss to quit work following suspension, disclosure of mental illness and reason for regretting disclosure, reasons for being denied employment, job rotation, reasons for retirement, reasons for working, whether they had been told to work by their family, and consulting for people with mental illness). Post hoc comparisons was used to assess differences in rates between groups of demographic characteristics. Factor analysis using the major factor method and promax rotation was used to examine the factor structure of the Rosenberg Self-Esteem Scale Japanese version. A $p$-value $<.05$ was considered to indicate statistical significance, and all statistical tests were two-tailed.

\section{Results}

\subsection{Participant Characteristics}

A total of 270 completed questionnaires were returned by participants. There were 191 valid responses (Figure 1). No participants reported currently being in general employment.

The majority of valid responses (69.1\%) were received from males. Most study participants were in their 30s or 40s (33\% and 30.9\% respectively), with younger (20s) and older $(\geq 50)$ age groups each making up approximately $18 \%$ of the sample. Education: junior high school, 20 (10.5\%); high school, 92 (48.2\%); occupational school, 24 (12.5\%); junior college, 8 (4.2\%); university, 47 (24.6\%). Mental illness: schizophrenia, 103 (53.9\%); mood disorder, 38 (19.9\%); developmental disorder, 50 (26.2\%). Age at onset: 19 or younger, 58 (30.4\%); 20s, 88 (46.1\%); 30s, 27 (14.1\%); 40s or older, 18 (9.4\%). Psychiatric hospitalisation: once, 41 (21.5\%); between two and four times, 50 (26.2\%); between five and nine times, 18 (9.4\%); 10 or more times, 12 (6.3\%); never, 70 (36.6\%). Source (s) of income (multiple choice): have earned income, 106 (55.5\%); dependent on family, 52 (27.2\%); disability pension, 116 (60.7\%); public assistance, 30 (15.7\%); other, 11 (5.8\%). Disclosure of mental illness to boss: yes, 91 (47.7\%); no, 86 (45.0\%); do not recall, 14 (7.3\%); other characteristics (Table 1). 


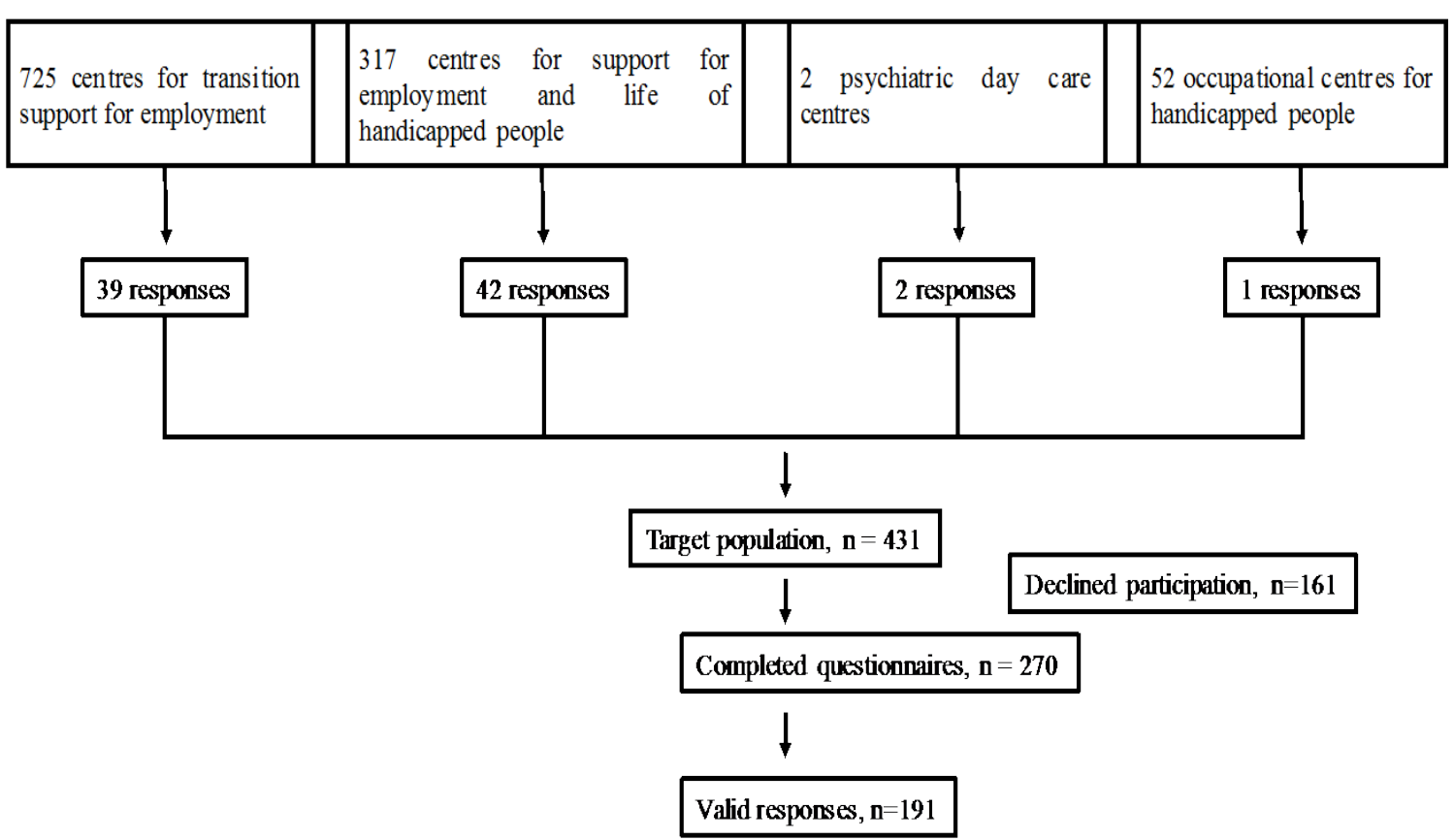

Figure 1. Schematic diagram illustrating sample composition.

\subsection{Rosenberg Self-Esteem Scale Japanese Version (RSES-J) Score}

The highest score for self-esteem among the questions was for question 7 and 10: I feel that I'm a person of worth, at least on an equal plane with others, I take a positive attitude toward myself (median $=3.0$, IQR: 2.0, 3.0) (Table 2).

\subsection{The Factor Analysis of Rosenberg Self-Esteem Scale Japanese Version}

The factor analysis of the RSES-J revealed two factors. Factor 1 loaded items 1, 3, 4, 5, 7, and 10 (proportion of variance, 39.7\%; $\alpha$ coefficient, .79), and factor 2 loaded items 2, 6, 8, and 9 (proportion of variance, 14.2\%; $\alpha$ coefficient, .66) (Table 3).

\subsection{Workplace Social Distance Scale (WSDS) Score}

The highest score for self-stigma among the WSDS questions was for question 7: If I needed a babysitter for the in-house nursery, I would be willing to hire a woman with psychosis (median = 2.0, IQR: 1.0, 2.0) (Table 4).

\subsection{Characteristics Associated with RSES-J and WSDS Scores}

For RSES-J, the results of the Kruskal-Wallis test showed significant differences in the scores for participants affiliated with different types of support facilities (Table 5) and those of different ages at the onset of mental illness $(p<.05)$. Post hoc comparisons showed significant differences in scores between participants who had attended centres for support for employment and the life of handicapped people and those who had attended psychiatric day care centres $(p=.003)$. Post hoc comparisons showed significant differences in scores between participants who had attended centres for transition support for employment and those who had attended psychiatric day care centres $(p=.017)$. The results of the Mann-Whitney $U$ test showed significant differences by psychiatric hospitalisation, presence of earned income, experiences of working part-time, experiences of being treated coldly at work, turning to family or a family doctor for consultation, being denied employment because of the lack of employable skills or because of having psychosis (Table 5) and citing family members telling them to work as the reason for working (Table 5) $(p<.05)$. Scores were lower for those who had consulted family than for those who had not (median = 22.0; IQR: 17.0, 25.0 vs. median $=24.0$; IQR: 20.25, 27.0) and for those who had consulted a family doctor than for those who had not (median =21.0; IQR: 15.0, 25.0 vs. median 
Table 1. Participants’ demographic characteristics $(n=191)$.

Type of employment experienced after onset of mental illness (multiple choice)

Regular employee

Part-time worker

Contract worker

Unfair experiences at work (multiple choice)

Treated coldly

Low salary

Made to transfer

Not being taught how to work

Long working hours

Other

No such experiences

Reason(s) for being treated unfairly (multiple choice)

Psychosis

Interpersonal relationship

Mistakes made at work

Reason(s) unclear

No such experiences

Quit work after onset of mental illness (multiple choice)

Quit voluntarily

Dismissed

Other

Continued working

Reason for regretting disclosure of mental illness

Change of peoples' attitude

Lower salary, transfer, other change in conditions

No disclosure or no regret

Advised by boss to quit work following suspension

Yes

No

Do not recall

= 24.0; IQR: 20.25, 27.0).

WSDS scores were higher for those who were not living alone than for those who were living alone (median $=8.0$; IQR: 5.0, 10.75 vs. median $=6.0$; IQR: 3.0, 10.0; Mann-Whitney $U$ test: $p<.05$ ). WSDS scores were higher for those who did not disclose their mental illness to their colleagues than for those who did (median $=$ 
Table 2. Rosenberg self-esteem scale Japanese version (RSES-J) score (n = 191).

\begin{tabular}{|c|c|c|c|}
\hline \multirow[t]{2}{*}{ No. } & \multirow[t]{2}{*}{ Item } & $\begin{array}{l}\text { Strongly agree } \\
\text { Agree } \\
\text { Disagree } \\
\text { Strongly disagree }\end{array}$ & Median \\
\hline & & N (\%) & (IQR) \\
\hline \multirow{4}{*}{ Q1 } & \multirow{4}{*}{ On the whole, I am satisfied with myself. } & $11(5.8)$ & 2.0 \\
\hline & & $67(35.1)$ & $(2.0,3.0)$ \\
\hline & & $73(38.2)$ & \\
\hline & & 40 (20.9) & \\
\hline \multirow{4}{*}{$\mathrm{Q}^{*}$} & \multirow{4}{*}{ At times, I think I am no good at all. } & $49(25.7)$ & 2.0 \\
\hline & & $91(47.6)$ & $(1.0,3.0)$ \\
\hline & & $38(19.9)$ & \\
\hline & & $13(6.8)$ & \\
\hline \multirow{4}{*}{ Q3 } & \multirow{4}{*}{ I feel that I have a number of good qualities. } & $11(5.8)$ & 2.0 \\
\hline & & $80(41.9)$ & $(2.0,3.0)$ \\
\hline & & $74(38.7)$ & \\
\hline & & $26(13.6)$ & \\
\hline \multirow{4}{*}{ Q4 } & \multirow{4}{*}{ I am able to do things as well as most other people. } & $9(4.7)$ & 2.0 \\
\hline & & $69(36.1)$ & $(2.0,3.0)$ \\
\hline & & $81(42.4)$ & \\
\hline & & $32(16.8)$ & \\
\hline \multirow{4}{*}{$\mathrm{Q}^{*}$} & \multirow{4}{*}{ I feel I do not have much to be proud of. } & $30(15.7)$ & 2.0 \\
\hline & & $84(44.0)$ & $(2.0,3.0)$ \\
\hline & & $57(29.8)$ & \\
\hline & & $20(10.5)$ & \\
\hline \multirow{4}{*}{$\mathrm{Q6}^{*}$} & \multirow{4}{*}{ I am able to do things as well as most other people. } & $40(20.9)$ & 2.0 \\
\hline & & $86(45.0)$ & $(2.0,3.0)$ \\
\hline & & $54(28.3)$ & \\
\hline & & $11(5.8)$ & \\
\hline \multirow{4}{*}{ Q7 } & \multirow{4}{*}{$\begin{array}{l}\text { I feel that I'm a person of worth, at least on an } \\
\text { equal plane with others. }\end{array}$} & $13(6.8)$ & 3.0 \\
\hline & & $83(43.5)$ & $(2.0,3.0)$ \\
\hline & & $69(36.1)$ & \\
\hline & & $26(13.6)$ & \\
\hline \multirow{4}{*}{$\mathrm{Q}^{*}$} & \multirow{4}{*}{ I wish I could have more respect for myself. } & $42(22.0)$ & 2.0 \\
\hline & & $106(55.5)$ & $(2.0,2.0)$ \\
\hline & & $29(15.2)$ & \\
\hline & & $14(7.3)$ & \\
\hline \multirow{4}{*}{$\mathrm{Q9}^{*}$} & \multirow{4}{*}{ All in all, I am inclined to feel that I am a failure. } & $38(19.9)$ & 2.0 \\
\hline & & $79(41.4)$ & $(2.0,3.0)$ \\
\hline & & $61(31.9)$ & \\
\hline & & $13(6.8)$ & \\
\hline \multirow{4}{*}{ Q10 } & \multirow{4}{*}{ I take a positive attitude toward myself. } & $33(17.3)$ & 3.0 \\
\hline & & $92(48.2)$ & $(2.0,3.0)$ \\
\hline & & $42(22.0)$ & \\
\hline & & 24 (12.6) & \\
\hline
\end{tabular}

"Reversal item. 
Table 3. Factor loadings for the rosenberg self-esteem scale Japanese version (major factor method and promax rotation).

\begin{tabular}{lcc}
\hline \multicolumn{1}{c}{ No. of RSES-J item } & Factor 1 & Factor 2 \\
\hline Factor 1 & .489 & .157 \\
Q1. On the whole, I am satisfied with myself. & .723 & -.077 \\
Q3. I feel that I have a number of good qualities. & .662 & .032 \\
Q4. I am able to do things as well as most other people. & .189 & .427 \\
Q5. I feel I do not have much to be proud of. & .583 & .005 \\
Q7. I feel that I'm a person of worth, at least on an equal plane with others. & .657 & .512 \\
Q10. I take a positive attitude toward myself. & .080 & .812 \\
Factor 2 & -.005 & .393 \\
Q2. At times, I think I am no good at all. & -.396 & .810 \\
Q6. I am able to do things as well as most other people. & -.018 & 1.417 \\
Q8. I wish I could have more respect for myself. & 3.969 & 14.168 \\
Q9. All in all, I am inclined to feel that I am a failure. & 39.688 & .79 \\
Eigenvalue
\end{tabular}

*Factor loadings $>0.5$ were considered acceptable.

8.0; IQR: 5.0, 11.0 vs. median = 6.0; IQR: 3.0, 8.25; Kruskal-Wallis test: $p<.05$ ). Those who did not work to make a living had higher scores than did those who did work to make a living (median = 9.0; IQR: 4.75, 14.0 vs. median = 7.0; IQR: 4.0, 10.0; Mann-Whitney $U$ test: $p<.05$ ).

\section{Discussion}

\subsection{Self-Esteem among People with Mental Illness Who Have Work Experience}

The scores of those who attended psychiatric day care were significantly higher than others, and the scores of participants who attended centres for transition support for employment were significantly lower. This result contradicts our expectation that the self-esteem scores of those who attend psychiatric day care would be low because for them it is chiefly a place to feel at home, and that the scores of those who attend centres for transition support for employment would be high because they have employment support training to start working. We could not clarify the reason for this finding in the process of our study; further research in this area will be needed. Several previous studies provide useful information in terms of helping people with mental illnesses to improve their self-esteem. A study targeting people with epilepsy indicated that support groups improve selfesteem (Sawangchareon et al., 2013) and another report has confirmed that forgiveness therapy is effective in improving resilience, self-esteem and spirituality among the wives of men suffering from alcohol misuse (Kim \& Lee, 2014). Another study has pointed out that medication monitoring and strengthening of work habits can improve self-esteem, thereby strengthening hope of recovery from illness, leading to the conclusion that vocational rehabilitation can enhance self-esteem (Gandhi et al., 2014). Based on the results above, we conclude that it is necessary to aim to find suitable jobs, improve the working skills of people with mental illness and, at the same time, ensure therapeutic involvement to heighten their self-esteem. We have shown, for example, that the self-esteem scores of those who thought that they were not employed because they had no employable skills were low (Table 5), and that only half of participants became regular employees after the onset of their mental illness (Table 1). These people might be successful in improving their self-esteem through acquiring useful qualifications for work and becoming regular employees. 
Table 4. Workplace Social Distance Scale (WSDS) scores $(\mathrm{n}=191)$.

\begin{tabular}{|c|c|c|c|}
\hline No. & $\begin{array}{c}\text { Item: Strongly agree } \\
\text { Agree } \\
\text { Disagree } \\
\text { Strongly disagree } \\
\text { N (\%) }\end{array}$ & & Median (IQR) \\
\hline \multirow{4}{*}{$\mathrm{Q} 1^{*}$} & \multirow{4}{*}{$\begin{array}{l}\text { It is best not to associate with a co-worker with } \\
\text { psychosis who has been in a mental hospital. }\end{array}$} & 87 (45.5) & $1.0(.0,1.0)$ \\
\hline & & $62(32.5)$ & \\
\hline & & $27(14.1)$ & \\
\hline & & 15 (7.9) & \\
\hline \multirow{4}{*}{ Q2 } & \multirow{4}{*}{$\begin{array}{l}\text { It is wrong to shy away from a } \\
\text { co-worker with psychosis. }\end{array}$} & 17 (8.9) & $.0(.0,1.0)$ \\
\hline & & 25 (13.1) & \\
\hline & & 45 (23.6) & \\
\hline & & $104(54.4)$ & \\
\hline \multirow{4}{*}{$\mathrm{Q3}^{*}$} & \multirow{4}{*}{$\begin{array}{l}\text { It would bother me to work next to } \\
\text { a co-worker with psychosis. }\end{array}$} & 77 (40.3) & $1.0(.0,1.0)$ \\
\hline & & $71(37.2)$ & \\
\hline & & $31(16.2)$ & \\
\hline & & $12(6.3)$ & \\
\hline \multirow{4}{*}{$\mathrm{Q}^{*}$} & \multirow{4}{*}{$\begin{array}{l}\text { I would not ride in a car driven } \\
\text { by a co-worker with psychosis. }\end{array}$} & $65(34.0)$ & $1.0(.0,2.0)$ \\
\hline & & 59 (30.9) & \\
\hline & & 37 (19.4) & \\
\hline & & 30 (15.7) & \\
\hline \multirow{4}{*}{ Q5 } & \multirow{4}{*}{$\begin{array}{l}\text { I would rather not hire a person with } \\
\text { psychosis who had been in a hospital. }\end{array}$} & $11(5.8)$ & $1.0(.0,1.0)$ \\
\hline & & 31 (16.2) & \\
\hline & & 62 (32.5) & \\
\hline & & $87(45.5)$ & \\
\hline \multirow{4}{*}{$\mathrm{Q6}^{*}$} & \multirow{4}{*}{$\begin{array}{l}\text { Bosses with psychosis should not be allowed to } \\
\text { teach how to work at the workplace. }\end{array}$} & $105(55.0)$ & $.0(.0,1.0)$ \\
\hline & & 57 (29.8) & \\
\hline & & 17 (8.9) & \\
\hline & & $12(6.3)$ & \\
\hline \multirow{4}{*}{ Q7 } & \multirow{4}{*}{$\begin{array}{l}\text { If I needed a babysitter for the in-house nursery, } \\
\text { I would be willing to hire a woman with psychosis. }\end{array}$} & 37 (19.4) & $2.0(1.0,2.0)$ \\
\hline & & 62 (32.5) & \\
\hline & & 47 (24.6) & \\
\hline & & 45 (23.6) & \\
\hline \multirow{4}{*}{$\mathrm{Q8}^{*}$} & \multirow{4}{*}{$\begin{array}{l}\text { I would be against any secretary } \\
\text { of mine marryinga man with psychosis. }\end{array}$} & $98(51.3)$ & $.0(.0,1.0)$ \\
\hline & & $51(26.7)$ & \\
\hline & & $19(9.9)$ & \\
\hline & & $23(12.0)$ & \\
\hline
\end{tabular}

*Reversal item. 
Table 5. Characteristics associated with RSES-J scores and WSDS scores $(n=191)$.

\begin{tabular}{|c|c|c|c|c|c|}
\hline & \multicolumn{3}{|c|}{${\underline{\text { WSDS }^{\mathrm{a}}}}$} & \multicolumn{2}{|l|}{$\underline{\text { RSES-J }^{d}}$} \\
\hline & n (\%) & Median (IQR) & $p$ & Median (IQR) & $p$ \\
\hline Type of support facility & & & $.408^{\mathrm{b}}$ & & $.005^{\mathrm{b}^{*}}$ \\
\hline Centre for transition support for employment & $84(44.0)$ & $6.0(3.0,10.0)$ & & $22.0(20.0,26.7)$ & \\
\hline Centre for support for employment and life of handicapped people & $51(26.7)$ & $8.0(5.0,10.0)$ & & $23.0(19.0,25.0)$ & \\
\hline Psychiatric day care centre & $26(13.6)$ & $9.0(3.0,12.25)$ & & $26.5(24.0,29.0)$ & \\
\hline Occupational centre for handicapped people & $30(15.7)$ & $8.0(4.0,10.5)$ & & $23.5(18.7,28.0)$ & \\
\hline \multicolumn{6}{|l|}{ Reason(s) for being denied employment } \\
\hline No employable skills & & & $.657^{\mathrm{c}}$ & & $.001^{\mathrm{c}^{*}}$ \\
\hline Yes & $47(24.6)$ & $6.0(4.0,10.0)$ & & $21.0(17.0,25.0)$ & \\
\hline No & $144(75.4)$ & $7.5(4.0,10.0)$ & & $24.0(21.0,27.0)$ & \\
\hline Psychosis & & & $.003^{c^{*}}$ & & $.028^{\mathrm{c}^{*}}$ \\
\hline Yes & $51(26.7)$ & $5.0(2.0,8.0)$ & & $22.0(19.0,25.0)$ & \\
\hline No & $140(73.3)$ & $8.0(4.0,11.0)$ & & $24.0(21.0,27.0)$ & \\
\hline Experience(s) of being treated coldly at work & & & $.990^{\mathrm{c}}$ & & $.004^{4^{*}}$ \\
\hline Yes & $54(28.3)$ & $7.0(3.75,10.0)$ & & $22.0(17.7,25.0)$ & \\
\hline No & $137(71.7)$ & $7.0(4.0,10.0)$ & & $24.0(21.0,27.5)$ & \\
\hline Being told to work by family & & & $.414^{\mathrm{c}}$ & & $.005^{c^{*}}$ \\
\hline Yes & $25(13.1)$ & $8.0(4.5,11.0)$ & & $19.0(15.5,25.0)$ & \\
\hline No & $166(86.9)$ & $7.0(4.0,10.0)$ & & $24.0(21.0,27.0)$ & \\
\hline
\end{tabular}

${ }^{\mathrm{a}}$ WSDS = Workplace Social Distance Scale, ${ }^{\mathrm{b}}$ Kruskal-Wallis test, ${ }^{\mathrm{c}}$ Mann-Whitney $U$ test, ${ }^{\mathrm{d}} \mathrm{RSES}-\mathrm{J}=$ Rosenberg Self-Esteem Scale Japanese version, * $p$-values $<.05$.

\subsection{Stigmatisation and Discrimination in the Workplace}

In a survey of actual conditions at Hello Work (public employment service) in Japan in 2009, among people with mental illnesses in general employment, about 40\% disclosed their illness and 60\% did not (Japan Organization for Employment of the Elderly, 2010). In our study, the percentages disclosing their illness to their boss was $47.7 \%$. About 22\% of the participants experienced dismissal after the onset of their mental illness (Table 1 ). Surprisingly, about $14 \%$ were advised by their bosses to quit (Table 1). As to company managers' opinions about people with mental illnesses, a review by Brohan and Thornicroft (2010) introduced a study targeting 502 entrepreneurs that identified the following concerns among managers: (1) worry about the safety of the other employees - that is, worry about the symptoms (17\%), assumptions that mentally ill people cannot cope with stress (14\%) and concerns about the possibility of strange and unpredicted behaviour (11\%); (2) worry about the capacity for work (20\%); (3) long absences (29\%); (4) necessity for observation and burden to management (7\%) and negative attitudes of colleagues (2\%). Because people at workplaces potentially have such opinions about people with mental illnesses, when the disease is disclosed, they may respond by stigmatising the patients. Problems of stigma experienced by people with mental illnesses at their workplaces are so serious that it is necessary to implement some measures for them to acquire employment opportunities and to continue working.

\subsection{Self-Stigma among People with Mental Illness Who Have Work Experience}

Many participants reported that they had an experience of unfair treatment, and about 18\% of them thought that it was because of their psychosis (Table 1). This result coincides with the statement by Corrigan and Watson 
(2002) that "mentally-disabled people apply the stereotypes to themselves (Because I have a mental illness, I am to blame for my problems)". Yanos et al. (2010) noted that "An accumulating body of evidence supports that internalised stigma, or self-stigma, is associated with compromised outcomes related to recovery from severe mental illness". Therefore, we conclude that supportive measures are necessary to help mitigate self-stigma. Such measures include those cited by Segal et al. (2013): "This study considered the relative effectiveness of self-help agencies (SHAs) and board-and staff-run consumer-operated service programmes (BSR-COSPs) working jointly with community mental health agencies (CMHAs) and the role of organisational empowerment in reducing self-stigma. These Members experienced reduced self-stigma and increases in self-efficacy when they were engaged in responsible roles". Roe et al. (2014) reported "the Narrative enhancement and cognitive therapy (NECT) treatment group showed significant $(p<.05)$ reductions in self-stigma and increases in self-esteem, quality of life, and Hope-Agency scores between pre-and post-treatment assessments, compared with the control group”. Based on the finding that self-esteem was significantly lower among those who attended centres for transition support for employment, supporters of those with mental illnesses need to be aware of the potentially low self-esteem of people with mental illnesses who have training for employment and, accordingly, to provide additional training. We need to improve working environments to ensure that people with mental illnesses can work by introducing countermeasures to stigma into employee education programmes in the workplace.

Finally, there are some limits to this study. First, memory biases and the cross-sectional research design may well have affected results. A longitudinal study design may have been more appropriate. Second, the questions were addressed to only the mental health outpatients. The amount of stigmatisation toward mental illness expressed by individuals in the workplace was unclear. Third, as type of facility correlated with some of the study variables, and as some form of selection took place by the directors of the health service provision, these factors may have affected the main finding.

\section{Conclusion}

It is necessary to improve working environments to ensure that people with mental illnesses can work by introducing anti-stigma countermeasures in the workplace.

\section{Acknowledgements}

We thank the facilities and the people who have cooperated with our survey.

\section{References}

Boyd, J. E., Otilingam, P. G., \& Deforge, B. R. (2014). Brief Version of the Internalized Stigma of Mental Illness (ISMI) Scale: Psychometric Properties and Relationship to Depression, Self Esteem, Recovery Orientation, Empowerment, and Perceived Devaluation and Discrimination. Psychiatric Rehabilitation Journal, 37, 17-23. http://dx.doi.org/10.1037/prj0000035

Brohan, E., \& Thornicroft, G. (2010). Stigma and Discrimination of Mental Health Problems: Workplace Implications. Occupational Medicine (London), 60, 414-415. http://dx.doi.org/10.1093/occmed/kqq048

Cavelti, M., Kvrgic, S., Beck, E. M., Rüsch, N., \& Vauth, R. (2012). Self-Stigma and Its Relationship with Insight, Demoralization, and Clinical Outcome among People with Schizophrenia Spectrum Disorders. Comprehensive Psychiatry, 53, 468-479. http://dx.doi.org/10.1016/j.comppsych.2011.08.001

Corrigan, P. W., Sokol, K. A., \& Rüsch, N. (2013). The Impact of Self-Stigma and Mutual Help Programs on the Quality of Life of People with Serious Mental Illnesses. Community Mental Health Journal, 49, 1-6. http://dx.doi.org/10.1007/s10597-011-9445-2

Corrigan, P., \& Watson, A. (2002). The Paradox of Self-Stigma and Mental Illness. Clinical Psychology: Science and Practice, 9, 35-53. http://dx.doi.org/10.1093/clipsy.9.1.35

Gandhi, S., Pavalur, R., Thanapal, S., Parathasarathy, N. B., Desai, G., Bhola, P., Philip, M., \& Chaturvedi, S. K. (2014). Medication Adherence, Work Performance and Self-Esteem among Psychiatric Patients Attending Psychosocial Rehabilitation Services at Bangalore, India. Indian Journal of Psychological Medicine, 36, 392-396. http://dx.doi.org/10.4103/0253-7176.140724

Japan Organization for Employment of the Elderly (2010) Persons with Disabilities and Job Seekers. A Study on the Employment Conditions, etc., to Promote Employment of Persons with Mental Disabilities (Research Report No. 95).

Kahng, S. K., \& Mowbray, C. T. (2005). What Affects Self-Esteem of Persons with Psychiatric Disabilities: The Role of 
Causal Attributions of Mental Illnesses. Psychiatric Rehabilitation Journal, 28, 354-361. http://dx.doi.org/10.2975/28.2005.354.360

Kim, H. K., \& Lee, M. (2014). Effectiveness of Forgiveness Therapy on Resilience, Self-Esteem, and Spirituality of Wives of Alcoholics. Journal of Korean Academy of Nursing, 44, 237-247. http://dx.doi.org/10.4040/jkan.2014.44.3.237

Livingston, J. D., Rossiter, K. R., \& Verdun-Jones, S. N. (2011). “Forensic” Labelling: An Empirical Assessment of Its Effects on Self-Stigma for People with Severe Mental Illness. Psychiatry Research, 188, 115-122. http://dx.doi.org/10.1016/j.psychres.2011.01.018

Mimura, C., \& Griffiths, P. (2007). A Japanese Version of the Rosenberg Self-Esteem Scale: Translation and Equivalence Assessment. Journal of Psychosomatic Research, 62, 589-594. http://dx.doi.org/10.1016/j.jpsychores.2006.11.004

Roe, D., Hasson-Ohayon, I., Mashiach-Eizenberg, M., Derhy, O., Lysaker, P. H., \& Yanos, P. T. (2014). Narrative Enhancement and Cognitive Therapy (NECT) Effectiveness: A Quasi-Experimental Study. Journal of Clinical Psychology, 70, 303-312. http://dx.doi.org/10.1002/jclp.22050

Rüsch, N., Nordt, C., Kawohl, W., Brantschen, E., Bärtsch, B., Müller, M., Corrigan, P. W., \& Rössler, W. (2014). WorkRelated Discrimination and Change in Self-Stigma among People with Mental Illness during Supported Employment. Psychiatric Services, 65, 1496-1498. http://dx.doi.org/10.1176/appi.ps.201400073

Sawangchareon, K., Pranboon, S., Tiamkao, S., \& Sawanyawisuth, K. (2013). Moving the Self-Esteem of People with Epilepsy by Supportive Group: A Clinical Trial. Journal of Caring Sciences, 2, 329-335.

Segal, S. P., Silverman, C. J., \& Temkin, T. L. (2013). Self-Stigma and Empowerment in Combined-CMHA and ConsumerRun Services: Two Controlled Trials. Psychiatric Services, 64, 990-996. http://dx.doi.org/10.1176/appi.ps.201200490

Watson, A. C., Corrigan, P., Larson, J. E., \& Sells, M. (2007). Self-Stigma in People with Mental Illness. Schizophrenia Bulletin, 33, 1312-1318. http://dx.doi.org/10.1093/schbul/sbl076

Yanos, P. T., Roe, D., \& Lysaker, P. H. (2010). The Impact of Illness Identity on Recovery from Severe Mental Illness. American Journal of Psychiatric Rehabilitation, 13, 73-93. http://dx.doi.org/10.1080/15487761003756860

Yoshii, H., Mandai, N., Saito, H., \& Akazawa, K. (2014). Reliability and Validity of the Workplace Social Distance Scale. Global Journal of Health Science, 7, 46-51. http://dx.doi.org/10.5539/gjhs.v7n3p46

\section{Submit or recommend next manuscript to SCIRP and we will provide best service for you:}

Accepting pre-submission inquiries through Email, Facebook, LinkedIn, Twitter, etc.

A wide selection of journals (inclusive of 9 subjects, more than 200 journals)

Providing 24-hour high-quality service

User-friendly online submission system

Fair and swift peer-review system

Efficient typesetting and proofreading procedure

Display of the result of downloads and visits, as well as the number of cited articles

Maximum dissemination of your research work

Submit your manuscript at: http://papersubmission.scirp.org/ 